\title{
RESPONSE ANALYSIS OF CONCRETE PILES SUBJECTED TO LATERAL IMPACT
}

\author{
Helsin Wang \\ Department of Construction Engineering, National Taiwan University of Science and Technology (Taiwan Tech), \\ Taipei, Taiwan, R.O.C, hswang@mail.ntust.edu.tw \\ Ta-Peng Chang \\ Department of Construction Engineering, National Taiwan University of Science and Technology (Taiwan Tech), \\ Taipei, Taiwan, R.O.C \\ Jin-Jun Wang \\ Department of Civil Engineering, Army Academy, Chung-Li, Taoyuang, Taiwan, R.O.C
}

Follow this and additional works at: https://jmstt.ntou.edu.tw/journal

Part of the Civil and Environmental Engineering Commons

\section{Recommended Citation}

Wang, Helsin; Chang, Ta-Peng; and Wang, Jin-Jun (2010) "RESPONSE ANALYSIS OF CONCRETE PILES SUBJECTED TO LATERAL IMPACT," Journal of Marine Science and Technology. Vol. 18: Iss. 6, Article 9.

DOI: 10.51400/2709-6998.1943

Available at: https://jmstt.ntou.edu.tw/journal/vol18/iss6/9

This Research Article is brought to you for free and open access by Journal of Marine Science and Technology. It has been accepted for inclusion in Journal of Marine Science and Technology by an authorized editor of Journal of Marine Science and Technology. 


\title{
RESPONSE ANALYSIS OF CONCRETE PILES SUBJECTED TO LATERAL IMPACT
}

\author{
Helsin Wang*, Ta-Peng Chang*, and Jin-Jun Wang**
}

Key words: dispersive flexural waves, three-dimensional wave theory, resonant frequency, phase velocity.

\begin{abstract}
One-dimensional wave theory is assumed to interpret longitudinal waves impulse response or impact echo testing results in concrete piles. Transient flexural waves tests are alternatively introduced to evaluate piles where the tops are inaccessible for conventional longitudinal wave testing. The resulting interpretation for flexural waves based on one-dimensional wave theory is improper due to various velocities at low frequencies. In this research, treating a pile as a waveguide, three-dimensional wave theory provides the dispersion relation between phase flexural velocity and frequency. Using the resonance solutions and first-mode flexural wave curve is a simple and efficient method to find the resonant frequency and phase velocity by knowing pile dimension and flexural IR results. The phase velocities at resonant frequencies measured in several flexural wave tests have good matches with the first-mode wave theoretical predictions at frequencies below $3,000 \mathrm{~Hz}$. The boundary conditions for practical feasibility are discussed for different $i n$-situ conditions.
\end{abstract}

\section{INTRODUCTION}

Non-destructive testing (NDT) techniques have been applied to construction quality control for drilled shafts and concrete piles for more than forty years. Both the impulse response (IR) and impact echo (IE) methods are two most common techniques used to non-destructively evaluate the integrity of concrete piles in field. The in-service conditions of existing deep foundations, e.g., the evaluations of dimensions and continuity of pile foundations, usually have to been qualitatively evaluated by these two most popular methods [ 1 , $3,6,12,14]$.

Transient-state longitudinal (compressive) waves are commonly induced in conventional IR or IE tests at the top of pile

Paper submitted 07/06/09; revised 10/07/09; accepted 11/05/09. Author for correspondence: Helsin Wang (e-mail: hswang@mail.ntust.edu.tw).

*Department of Construction Engineering, National Taiwan University of Science and Technology (Taiwan Tech), Taipei, Taiwan, R.O.C.

**Department of Civil Engineering, Army Academy, Chung-Li, Taoyuang, Taiwan, R.O.C. foundations by a hammer while the top of piles is accessible to install testing equipment. When the top of concrete piles is inaccessible for testing, an approach of transient-state flexural wave induced by the lateral impact is an alternative, particularly applicable in the partially exposed piles of overwater structures, such as wharf and bridge $[5,8,9,11,18-21]$.

Normally the constant (non-dispersive) wave velocity onedimensional (1-D) wave theory is applied to interpret results of longitudinal wave IR or IE tests in concrete piles [4, 10, 21]. Using spectrum information can efficiently evaluate pile lengths or defect positions. On the contrary, the flexural wave velocities are varied with frequencies at low frequencies, overlapping with the induced frequency range in the IR or IE tests [5, $18,23]$. As a result, the feasibility of flexural wave with IR or IE tests is currently limited at high frequencies, especially improper for concrete piles with a high material attenuation $[13,21,23]$.

Using the 1-D wave theory may be insufficient to provide proper interpretation of transient flexural wave experimental results at low frequency. To efficiently apply the responses at the most excited frequency range in the flexural IR tests, the dispersion relation between phase velocity and frequency is introduced by using the three-dimensional (3-D) wave theory while the concept of a waveguide is applied to concrete piles. The phase velocities at resonant frequencies in flexural wave IR or IE tests compare with the 3-D flexural wave theoretical predictions. The practical application and limitation of phase velocities at resonant frequencies are also discussed in detail.

\section{ONE-DIMENSIONAL WAVE THEORY}

Consider that a given slender pile is subjected to the IR or IE testing, the induced longitudinal or flexural wavelength is normally much longer than the pile dimension, usually pile diameter. If the velocity of the induced stress waves is regarded as a constant, not a function of frequency, and the crosssectional displacement is uniform, the 1-D wave theory is intuitively assumed to interpret these testing results [10, 21, 22].

Figure 1 schematically shows the typical set for a traditional IR or IE test, called as the longitudinal IR or IE test herein, that includes a modal hammer, which produces an impact at the pile top or cap, and one or several fixed geophones or accelerometers at the pile top, which measure the surface vibration reflected from either the bottom of the pile or 


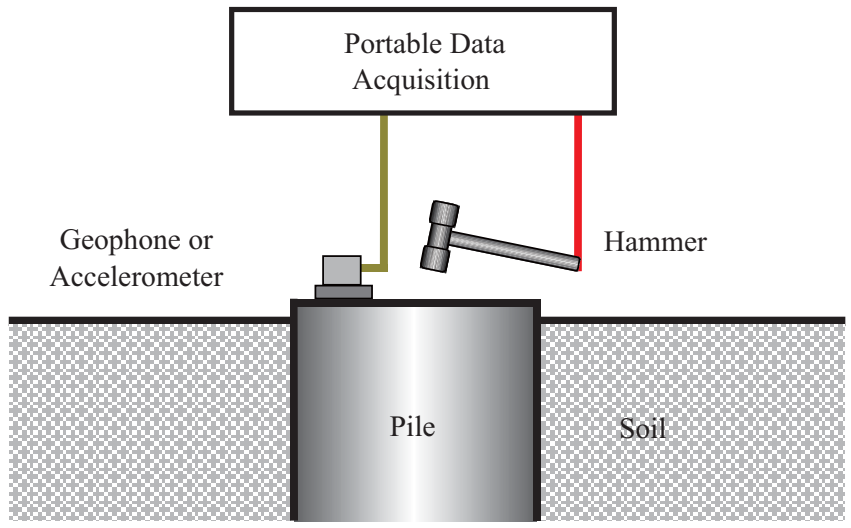

Fig. 1. Schematic arrangement of longitudinal impulse response testing.

defects in the pile along a longitudinal path parallel to the axial direction $[1,6,12,14,17]$. Both the force and velocity or acceleration signals are measured and digitally recorded in a portable data acquisition system. These time-domain signals are converted to the frequency domain or spectrum with a fast Fourier transfer (FFT) for further analysis. Conventionally, the bar wave velocity, $C_{b a r}$, in a concrete pile can be calculated from either the time domain or frequency domain data. In the time domain, the bar wave velocity, $C_{b a r}$, is computed by equation

$$
C_{b a r}=\frac{2 \ell}{\Delta t_{\text {avg }}}
$$

where $\ell$ is the distance between impact point and reflecting sources, either the bottom of a pile or a defect, and $\Delta t_{\text {avg }}$ the average traveling time between the impact point and reflection sources $[1,3,4,12]$. The computed wave velocity based on the time domain information usually represents a group velocity, namely the velocity of energy transportation of a wave [4]. In the frequency domain, the bar wave velocity, $C_{b a r}$, is computed by

$$
C_{b a r}=2 \ell \times f_{\text {peak }}
$$

where $f_{\text {peak }}$ is the maximum peak frequency $[3,4,14]$. The common bar wave velocity, $C_{b a r}$, of a sound concrete pile has a wide range from 3,500 to $4,500 \mathrm{~m} / \mathrm{sec}[3,12]$. If knowing the bar wave velocity, $C_{b a r}$, and second dominant peak frequency, $f_{\text {defect }}$, one can sketchily identify the significant defect position, $\ell_{\text {defect }}$, by re-grouping (2) as the following:

$$
\ell_{\text {defect }}=\frac{C_{\text {bar }}}{2 f_{\text {defect }}}
$$

The experimental procedures of the flexural wave method are similar to those of the conventional longitudinal IR or IE method. Figures 2(a) and 2(b) show two possible flexural IR or

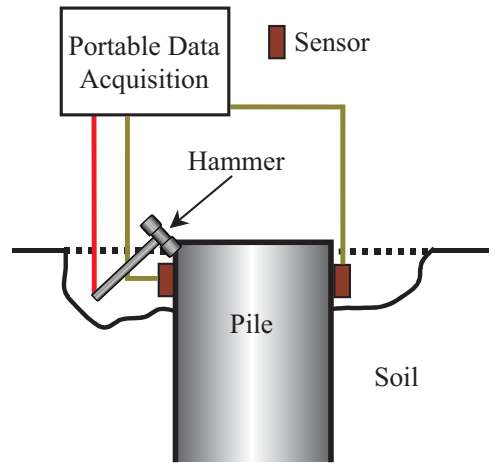

(a) Pile head exposed to the open space

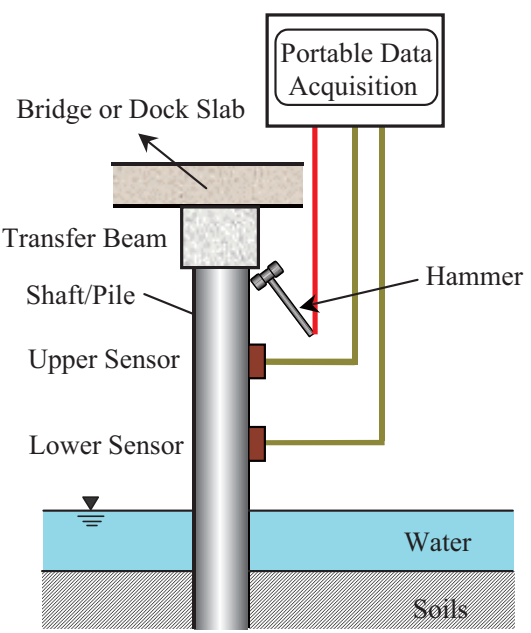

(b) Pile head connected to a beam

Fig. 2. Two schematic arrangements of flexural impulse response or impact echo testing.

IE tests conducted on a partially exposed concrete pile [5, 7-9, 16-20]. The former needs to remove a portion of topsoil surrounding the pile, while the latter is performed for the concrete shafts or piles connected to the docks, bridges, or wharves with lack of access to their tops. The transient-state flexural waves, traveling downward and upward along the pile, are induced by lateral impact on the free side of the concrete pile and recorded by two sensors mounted to either the opposite sides on the periphery or the same sides of the pile. The data of acceleration signals at time domain are stored in a portable data acquisition and converted to the frequency domain with FFT.

Usually, the apparent flexural wave velocity, $C_{s}$, in a concrete pile is computed in the time domain by

$$
C_{s}=\frac{D}{\Delta t}
$$

where $D$ is the distance between two sensors and $\Delta t$ is the traveling time between two sensors [5, 7-9, 16-20]. The flexural wave velocity, $C_{s}$, in a sound concrete pile commonly 


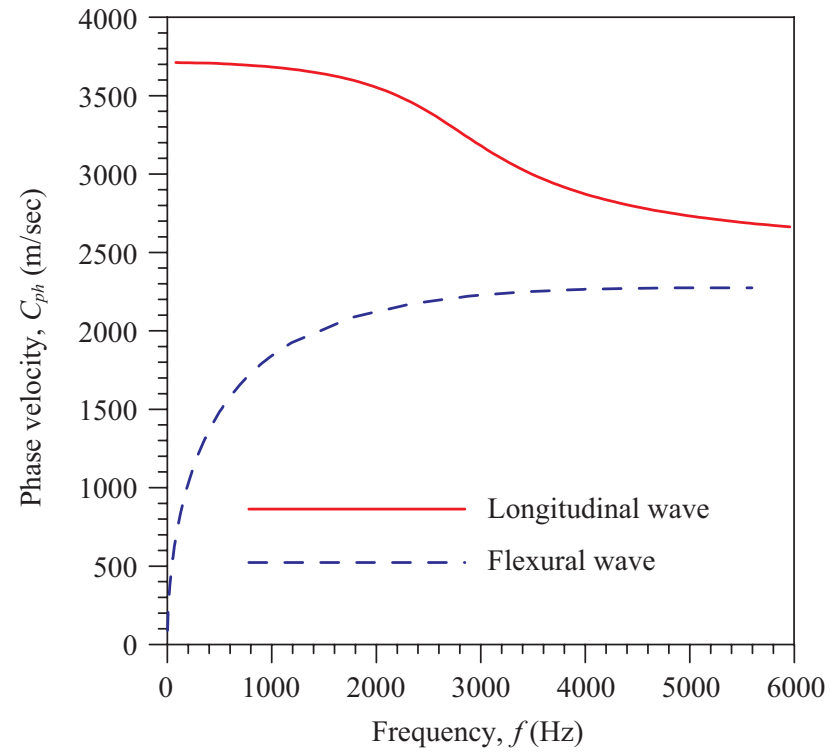

Fig. 3. Phase velocity curves of $L(0,1)$ and $F(1,1)$ in a $1-m$ diameter pile with shear wave velocity of $2,500 \mathrm{~m} / \mathrm{sec}$.

varies from 2,100 to $2,700 \mathrm{~m} / \mathrm{sec}$ [3], which can be applied to identify the pile lengths $[7-9,11,16-20,22]$ and localize the flaw positions $[5,18]$.

Frequency analysis currently is not recommended for the flexural IR or IE testing due to its dispersive characteristics, i.e., the wave velocity varied with frequency $[5,7-9,18,21]$. A numerical analysis based on the Timoshenko beam theory suggested that 1-D wave theory is acceptable in the flexural IR or IE testing for the resonant frequency modes higher than eight such that the wave velocity is approaching a constant value [23]. The analytic and experimental researches based on the three-dimensional wave theory supported the findings of non-dispersive flexural waves at higher frequencies in an embedded concrete pile with the same manner $[16,21]$.

\section{THREE-DIMENSIONAL WAVE THEORY}

\section{Longitudinal Waves}

The stress waves traveling in piles, called three-dimensional (3-D, guided) waves, include different clusters of waves arising from incidences and reflections of compression, shear, and surface waves along the boundaries of piles. The real wave velocity for such case is a function of frequency, and the displacement magnitudes vary along the pile cross-section. Theoretical and experimental investigations of the longitudinal and flexural waves in the prototype concrete piles embedded in a sand fill have been derived and verified, respectively $[4,13$, $16,21]$.

The maximum frequency generated generally reaches as high as 2 to $6 \mathrm{kHz}$ by hammer impacts used in longitudinal IR tests $[10,12]$. Its frequency range is located on the wave branch $\mathrm{L}(0,1)$, the first mode in the family of longitudinal modes with no radial displacement, derived from the guided wave theory, which is dispersive and varied with frequency as shown in Fig. 3. The phase velocity remains approximately a constant value around the bar wave velocity for frequencies below $2,000 \mathrm{~Hz}$, but approaches the Rayleigh wave velocity at frequency beyond $5,000 \mathrm{~Hz}$. Thus, a transient phase velocity monotonically decreasing from bar wave velocity to the Rayleigh wave velocity develops at frequency between 2,000 to $5,000 \mathrm{~Hz}$.

A transient-state (impact) wave can be considered as a superposition of many steady-state (3-D) waves [4]. The predominant waves excited by IR methods correspond to the low frequency range of the lowest branch of longitudinal guided waves in concrete piles and drilled shafts $[4,10]$. Due to the limitation of excited longitudinal waves within a low and narrow frequency range associated with IR tests, the wave velocities do not change much with frequency in concrete piles. Its longitudinal wave velocity in these narrow frequency ranges usually can be regarded as a constant that does not change with frequency [10] so as to the phase velocity in such a frequency range. Once the assumption of constant longitudinal wave velocity is accepted, the concept of 1-D waves, and not dispersive waves, is applied in general. Therefore, the 1-D wave theory used by the IR techniques is one special case of the 3-D wave theory at frequencies below $500 \mathrm{~Hz}$ and 6,000 $\mathrm{Hz}$ for pile diameters $2.4 \mathrm{~m}$ and $0.3 \mathrm{~m}$, respectively [21].

\section{Flexural Waves}

When the flexural waves on piles are introduced by a modal hammer, the most excited flexural waves are located within a low frequency range as those with a longitudinal IR method. Many experimental and theoretical investigations demonstrated the existence of dispersion of flexural waves in timber or concrete piles [5, 11, 17-23]. The phase velocity of flexural waves is no longer regarded as a constant value but various at low frequencies. The analytic solution of 3-D flexural wave theory suggests that the assumption of constant flexural wave velocity is acceptable only at frequencies of above $1,500 \mathrm{~Hz}$ to $10 \mathrm{kHz}$ for pile diameter of 2.4 to $0.3 \mathrm{~m}$, respectively [21]. This fact emphasizes the need to measure the flexural wave velocity directly at low frequencies, since it is not reasonable to assume a constant propagation velocity, as is commonly done for the longitudinal wave tests [11]. Using the 1-D wave theory may be insufficient to provide proper interpretation of experimental results [15].

Treating a pile as a wave guide, the lowest flexural wave branch $\mathrm{F}(1,1)$, the first mode in the series of flexural modes with one displacement cycle in the radial direction of the waveguide, is located within the most possible induced frequency range in the flexural wave tests [11]. Figure 3 also shows a typical dispersive phase velocity curve of branch $\mathrm{F}(1,1)$ for flexural waves traveling in a 1-meter diameter pile with a shear wave velocity of $2,500 \mathrm{~m} / \mathrm{sec}$. At low frequencies, the velocity value increases monotonically from zero to the Rayleigh wave velocity, 2,260 m/sec with frequency. For 


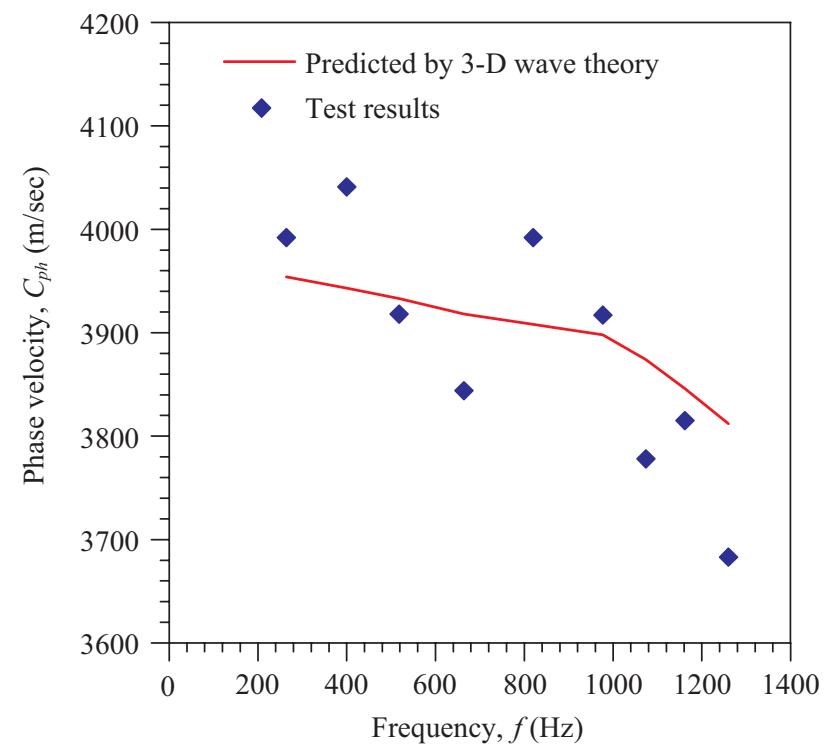

Fig. 4. Phase velocities of longitudinal waves in a drilled shaft [4].

frequency beyond $2,500 \mathrm{~Hz}$, the flexural wave velocity approaches the Rayleigh wave velocity. For such frequency range, the flexural wave velocity becomes apparently constant and non-dispersive with frequency, instead. The existence of plateaus for branch $\mathrm{F}(1,1)$ represents that the assumption of a constant velocity for flexural waves is valid only at high frequencies. On the other hand, the wave velocity of flexural waves induced by IR methods is dispersive at low frequencies by using 3-D wave theory. The constant velocity $1-\mathrm{D}$ wave theory cannot be used in explaining flexural wave results at low frequencies.

\section{Connection between 3-D Waves and Longitudinal and Flexural Wave IR Tests}

When conducting IR tests, either longitudinal waves or flexural waves, in concrete piles or drilled shafts, the incident waves on the pile top are supposed to be reflected on the pile bottom. The measured time is long enough to detect multiple reflections from the bottom, and arises resonance responses in concrete piles or shafts.

The resonant solutions of longitudinal IR tests in a finite embedded pile have been developed based on 1-D wave theory [4]. The longitudinal wave velocity in a low and narrow frequency ranges usually can be regarded as a constant that does not change with frequency. It is a special situation to find a regular resonant frequency from the longitudinal wave spectrum. It is the fundamental to use the resonant solutions and subsequently find its resonant frequency and phase velocity.

When the pile length is known, the phase velocity of longitudinal or flexural waves can be derived based on such a method. The experimental phase velocities are superimposed on 3-D wave theoretically-determined longitudinal wavecurve $\mathrm{L}(0,1)$. The IR experimental results are expected to lie along these theoretical prediction curves. This resonance technique has been already successfully applied to the longitudinal wave experimental results in concrete piles in few years ago. The computed phase velocity is given in Fig. 4 for the longitudinal wave results with an assumption of displacement $\mathrm{CB}$ conditions [4]. The results show a good trend between the $3-\mathrm{D}$ wave theoretical curve and IR experimental results. However, the same resonance technique has not yet been used to predict the resonant frequency and phase velocity in flexural wave experimental results due to changing velocity with frequency.

For flexural tests, the relevant numerical researches recommend that the frequency difference between two consecutive resonant frequencies at high frequencies approaches a constant value in piles, and the resonant frequencies measured from the flexural IR tests can be applied to evaluate pile lengths $[19,20,23]$. To the contrary, the dispersive flexural velocity arises an irregular frequency difference between two consecutive resonant frequencies at low frequencies which are the most excited frequency range in the flexural IR tests. This indicates that the resonant solutions in a finite embedded pile cannot be used in the same method as the situation in longitudinal wave experiments at low frequencies.

There are several disadvantages to use numerical analysis for flexural IR tests in piles. Relatively high attenuation in geomaterials, especially the embedded concrete piles herein, at high frequencies undermines the advantage of applying constant resonance difference [16, 21], not as expected in numerical analysis. The response at high frequencies is not easily excited and measured in concrete piles with flexural IR tests. In addition, most of these researches use numerical finite element method to circumvent the drawback in order to find the resonant frequency and phase velocity. A number of parameters about piles and site situation, including pile dimension, mechanical property, pile-to-soil interaction model, and engineering properties of soils, should be provided and determined in advance.

The whole process of data collection and analysis is timeconsuming and complicated by using numerical analysis. In this research, the resonance technique and first-mode flexural wave curve $F(1,1)$ are used to find the resonant frequency and phase velocity based on known pile dimension and flexural wave testing only. The experimental phase velocities are superimposed on 3-D wave theoretically-determined curve $\mathrm{F}(1,1)$ for flexural waves.

To efficiently apply the resonance responses at the most excited frequency range in the flexural IR tests, the resonance solutions of stress waves propagating in a finite embedded pile with a length of $L$ can be found as [2]

$$
\begin{aligned}
& \lambda_{d}=\frac{2 L}{n} \\
& \lambda_{s}=\frac{4 L}{2 n-1}
\end{aligned}
$$


Table 1. Physical properties of prototype concrete piles $[4,16]$.

\begin{tabular}{|l|c|c|c|}
\hline Property & Pile A & Pile B & Pile C \\
\hline Diameter & $0.355 \mathrm{~m}$ & $0.254 \mathrm{~m}$ & $0.308 \mathrm{~m}$ \\
\hline Length, $L$ & $2.43 \mathrm{~m}$ & $2.22 \mathrm{~m}$ & $2.4 \mathrm{~m}$ \\
\hline Bar wave velocity, $C_{b a r}$ & $3900 \mathrm{~m} / \mathrm{sec}$ & $4150 \mathrm{~m} / \mathrm{sec}$ & $4097 \mathrm{~m} / \mathrm{sec}$ \\
\hline Shear wave velocity, $C_{s}$ & $2530 \mathrm{~m} / \mathrm{sec}$ & $2625 \mathrm{~m} / \mathrm{sec}$ & $2592 \mathrm{~m} / \mathrm{sec}$ \\
\hline Poisson's ratio, $v$ & 0.2 & 0.25 & 0.28 \\
\hline
\end{tabular}

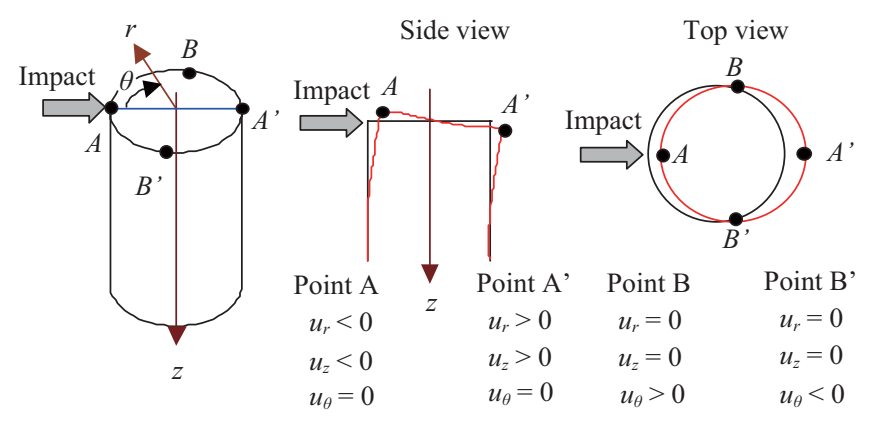

Fig. 5. Displacement responses for a pile subjected to a lateral impact.

respectively, where $\lambda_{d}$ is the resonant wavelength of waves with a displacement control boundary $(\mathrm{CB}), \lambda_{s}$ the resonant wavelength of waves with a stress $\mathrm{CB}$, and $n$ the positive integral resonant number. Each resonant frequency, $f_{n}$, is corresponding to a resonant number, $n$, and a resonant wavelength.

The phase velocity of longitudinal or flexural waves in a finite length pile can be measured in the frequency domain by means of an IR method. Generally, several resonant frequencies can be observed in IR testing results in concrete piles. The phase velocity, $C_{p h}$, for each resonant frequency, $f_{n}$, is defined as

$$
C_{p h}=\frac{\omega}{k}=\lambda \times f_{n}
$$

where $\omega$ is the angular frequency equal to $2 \pi f_{n}, k$ is the wave number equal to $2 \pi / \lambda$, and $\lambda$ is the resonant wavelength, either $\lambda_{d}$ or $\lambda_{s}$. The computed wave velocity based on the frequency domain information usually represents a phase velocity, i.e., the velocity of a particle on a wave $[4,11,22]$.

\section{Vibration Responses of Flexural IR Tests}

Impacts on the side of a pile are suggested as a method to induce transient-state flexural waves [4, 16-20]. The displacement responses for a fully or partially embedded pile subjected to a lateral impact at pile top are schematically shown in Fig. 5. The orthogonal cylindrical coordinate, $r-\theta-z$, system and the impact position (assumed $0^{\circ}$ ) are given in the left side of Fig. 5 . The expected deformation profiles from the side and top views are also shown. A warping-type displacement pattern occurs at top of the pile.
The displacement response at point $\mathrm{A}\left(\theta=0^{\circ}\right)$, the impact position, undergoes negative radial displacement, $u_{r}$, and negative axial displacement, $u_{z}$, with no angular displacement. The displacement response at point $\mathrm{A}^{\prime}\left(\theta=180^{\circ}\right)$ undergoes positive radial and positive axial displacements with no angular displacement, $u_{\theta}$. In practice, the displacements in the angular/tangential direction are normally negligible and the measurable displacements at positions $0^{\circ}$ and $180^{\circ}$ occur in the radial and longitudinal directions.

The displacements at points $\mathrm{B}\left(\theta=90^{\circ}\right)$ and $\mathrm{B}^{\prime}\left(\theta=270^{\circ}\right)$ undergo no radial and axial displacements, but positive and negative angular displacements, respectively. In practice, the displacements in the radial and longitudinal directions are normally negligible. At positions $90^{\circ}$ and $270^{\circ}$, the maximum displacement occurs in the angular/tangential direction. The analytic displacement responses for the first branch $\mathrm{F}(1,1)$ of the 3-D (steady-state) waves represent the displacement responses of transient flexural waves [20, 23].

\section{FLEXURAL WAVE IR TESTS ON CONCRETE PILES}

\section{Prototype Concrete Piles}

In this study, the flexural and longitudinal wave IR tests are conducted to three prototype concrete piles with different diameters of 0.254 to $0.355 \mathrm{~m}$ embedded in sandy fill (as the left side of Fig. 2). The physical properties of the three concrete piles are listed in Table $1[4,16]$.

The bar wave velocity and shear wave velocity are computed from the time-domain vibration responses. The Poisson's ratio in concrete is computed by the following equation:

$$
v=\frac{C_{b a r}{ }^{2}}{2 C_{s}{ }^{2}}-1
$$

The lateral impacts were conduced at point $\mathrm{A}$ (assumed $0^{\circ}$ ) with a modal hammer as that in Fig. 5. The vibration responses were measured with two triaxial accelerometers on the pile side after moving part of surrounding soils from the ground. The location and orientation of the transducer is consistent with the deformation induced by the impact. A typical FFT spectrum in the angular/tangential direction at positions $90^{\circ}$ and $270^{\circ}$ for pile A is shown in Fig. 6 .

A set of resonant peaks is found at frequencies below 3,000 
Table 2. Phase velocity computation using measured resonant frequency in prototype concrete pile $A$ at measurement positions $90^{\circ}$ and $270^{\circ}$ (angular/tangential direction) with stress and displacement control boundaries.

\begin{tabular}{|c|c|c|c|c|c|c|}
\hline \multirow[b]{3}{*}{$n$} & \multirow{3}{*}{ Position at $90^{\circ}$} & \multirow{3}{*}{ Position at $270^{\circ}$} & \multirow{2}{*}{\multicolumn{2}{|c|}{$\begin{array}{c}\text { Stress control boundary } \\
C_{p h} \\
\end{array}$}} & \multirow{2}{*}{\multicolumn{2}{|c|}{$\begin{array}{c}\text { Displacement control boundary } \\
C_{p h} \\
\end{array}$}} \\
\hline & & & & & & \\
\hline & & & $90^{\circ}$ & $270^{\circ}$ & $90^{\circ}$ & $270^{\circ}$ \\
\hline 1 & 51 & 51 & 496 & 496 & 248 & 248 \\
\hline 2 & 224 & 255 & 724 & 826 & 543 & 619 \\
\hline 3 & 549 & 529 & 1067 & 1029 & 889 & 858 \\
\hline 4 & 990 & 990 & 1375 & 1375 & 1203 & 1203 \\
\hline 5 & 1365 & 1373 & 1474 & 1482 & 1326 & 1334 \\
\hline 6 & 1839 & 1851 & 1625 & 1636 & 1490 & 1499 \\
\hline 7 & 2314 & 2333 & 1730 & 1745 & 1606 & 1620 \\
\hline 8 & 2706 & 2765 & 1753 & 1792 & 1644 & 1680 \\
\hline
\end{tabular}

Note $1: n$ is the resonant number, $f_{n}$ is the resonant frequency, and $C_{p h}$ is the phase velocity.

Note 2: Units of resonant frequency and phase velocity are $\mathrm{Hz}$ and $\mathrm{m} / \mathrm{sec}$, respectively.

Table 3. Phase velocity computation using measured resonant frequency in prototype concrete pile $A$ at measurement positions $0^{\circ}$ and $180^{\circ}$ (radial direction) with stress and displacement control boundaries.

\begin{tabular}{|c|c|c|c|c|c|c|}
\hline \multirow[b]{3}{*}{$n$} & \multirow{3}{*}{$\begin{array}{c}\text { Position at } 0^{\circ} \\
f_{n}\end{array}$} & \multirow{3}{*}{ Position at $180^{\circ}$} & \multirow{2}{*}{\multicolumn{2}{|c|}{$\frac{\text { Stress control boundary }}{C_{p h}}$}} & \multirow{2}{*}{\multicolumn{2}{|c|}{$\begin{array}{c}\text { Displacement control boundary } \\
C_{p h}\end{array}$}} \\
\hline & & & & & & \\
\hline & & & $0^{\circ}$ & $180^{\circ}$ & $0^{\circ}$ & $180^{\circ}$ \\
\hline 1 & 50 & 21 & 486 & 204 & 243 & 102 \\
\hline 2 & 220 & 230 & 713 & 745 & 535 & 559 \\
\hline 3 & 525 & 535 & 1021 & 1040 & 851 & 867 \\
\hline 4 & 915 & 925 & 1271 & 1284 & 1112 & 1124 \\
\hline 5 & 1365 & 1405 & 1474 & 1517 & 1327 & 1366 \\
\hline 6 & 1845 & $\mathrm{~N} / \mathrm{I}$ & 1630 & $\mathrm{~N} / \mathrm{I}$ & 1494 & $\mathrm{~N} / \mathrm{I}$ \\
\hline 7 & 2393 & 2285 & 1789 & 1708 & 1661 & 1586 \\
\hline 8 & 2785 & 2785 & 1805 & 1805 & 1692 & 1692 \\
\hline
\end{tabular}

Note $1: n$ is the resonant number, $f_{n}$ is the resonant frequency, $C_{p h}$ is the phase velocity, and N/I indicates not identified.

Note 2: Units of resonant frequency and phase velocity are $\mathrm{Hz}$ and $\mathrm{m} / \mathrm{sec}$, respectively.

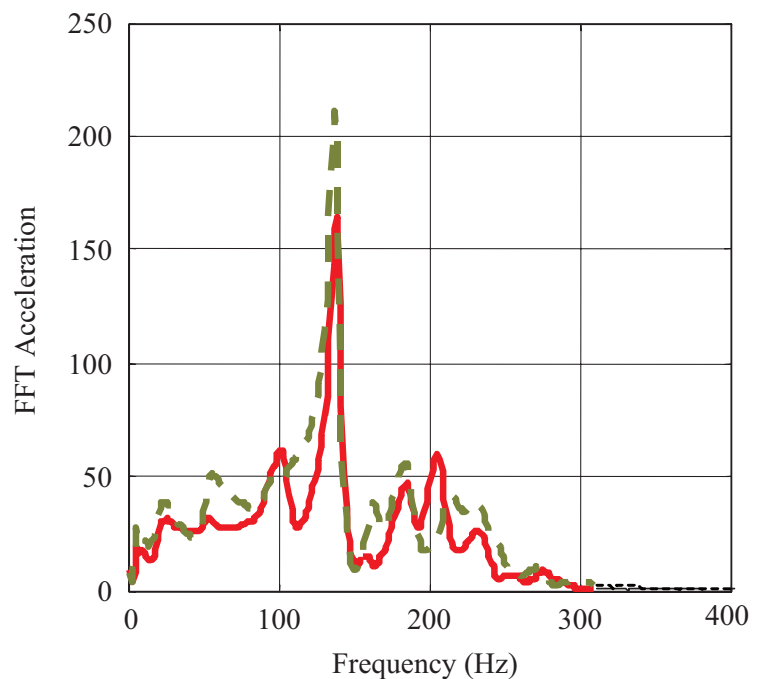

Fig. 6. Flexural impact results on a prototype concrete pile (Solid and dashed lines represent measurement positions at $90^{\circ}$ and $270^{\circ}$, respectively).
Hz. The first eight measured resonant frequencies are indicated in Table 2. The resonant number, $n$, is listed in the first column of Table 2. The identified resonant frequencies are listed in the second and third columns of Table 2 at positions $90^{\circ}$ and $270^{\circ}$, respectively. Similar resonant frequency values are observed by two accelerometers. In view of resonance principle, since the resonant frequencies for a wave traveling in a concrete pile are independent on their measurement positions, the same resonant frequencies at different measurement positions are theoretically expected. The phase velocities corresponding to resonant frequency are computed in the rest columns of Table 2 by using (7) for stress and displacement CBs. The similar phase velocity computations using resonant frequencies measured at positions $0^{\circ}$ and $180^{\circ}$ in the radial and longitudinal directions are also listed in Tables 3 and 4, respectively.

The flexural wave IR experimental results are superimposed on the theoretical prediction curve $\mathrm{F}(1,1)$ illustrated in Figs. 7 to 9 . Since the induced frequency generated by a 
Table 4. Phase velocity computation using measured resonant frequency in prototype concrete pile $\mathrm{A}$ at measurement positions $0^{\circ}$ and $180^{\circ}$ (longitudinal direction) with stress and displacement control boundaries.

\begin{tabular}{|c|c|c|c|c|c|c|}
\hline \multirow[b]{3}{*}{$n$} & \multirow{3}{*}{$\begin{array}{c}\text { Position at } 0^{\circ} \\
f_{n}\end{array}$} & \multirow{3}{*}{$\begin{array}{c}\text { Position at } 180^{\circ} \\
f_{n}\end{array}$} & \multirow{2}{*}{\multicolumn{2}{|c|}{$\begin{array}{c}\text { Stress control boundary } \\
C_{p h}\end{array}$}} & \multirow{2}{*}{\multicolumn{2}{|c|}{$\begin{array}{c}\text { Displacement control boundary } \\
C_{p h}\end{array}$}} \\
\hline & & & & & & \\
\hline & & & $0^{\circ}$ & $180^{\circ}$ & $0^{\circ}$ & $180^{\circ}$ \\
\hline 1 & $\mathrm{~N} / \mathrm{I}$ & $\mathrm{N} / \mathrm{I}$ & $\mathrm{N} / \mathrm{I}$ & N/I & $\mathrm{N} / \mathrm{I}$ & $\mathrm{N} / \mathrm{I}$ \\
\hline 2 & 220 & 210 & 713 & 680 & 535 & 510 \\
\hline 3 & 515 & 530 & 1001 & 1030 & 834 & 858.6 \\
\hline 4 & 915 & 915 & 1271 & 1271 & 1112 & 1112 \\
\hline 5 & 1365 & 1380 & 1474 & 1490 & 1327 & 1341 \\
\hline 6 & 1870 & $\mathrm{~N} / \mathrm{I}$ & 1652 & $\mathrm{~N} / \mathrm{I}$ & 1515 & $\mathrm{~N} / \mathrm{I}$ \\
\hline 7 & 2285 & $\mathrm{~N} / \mathrm{I}$ & 1708 & $\mathrm{~N} / \mathrm{I}$ & 1586 & $\mathrm{~N} / \mathrm{I}$ \\
\hline 8 & 2714 & 2750 & 1759 & 1782 & 1649 & 1671 \\
\hline
\end{tabular}

Note $1: n$ is the resonant number, $f_{n}$ is the resonant frequency, $C_{p h}$ is the phase velocity, and N/I indicates not identified.

Note 2: Units of resonant frequency and phase velocity are $\mathrm{Hz}$ and $\mathrm{m} / \mathrm{sec}$, respectively.

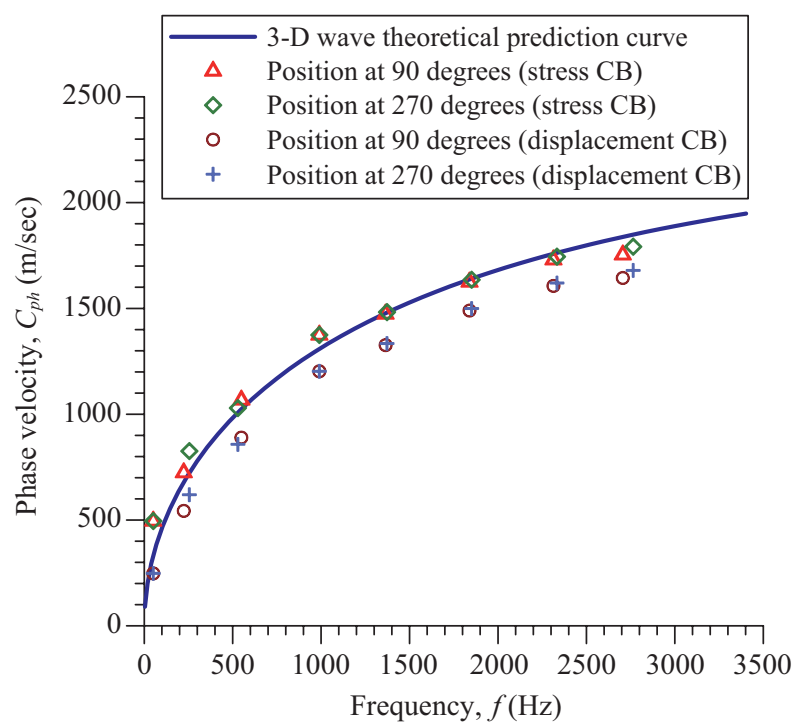

Fig. 7. Phase velocities of flexural waves a prototype concrete pile at measurement positions $90^{\circ}$ and $270^{\circ}$ (angular/tangential direction).

modal hammer ranges less than $4,000 \mathrm{~Hz}$ on concrete piles, the resulting phase velocities can be described by flexural wave curve $\mathrm{F}(1,1)$. The phase velocities at identified resonant frequencies monotonically increase with frequency and have similar velocity trends with $3-\mathrm{D}$ wave theoretical predictions. The analysis results agree with the conclusions published in $[4,11$, 16]. Most of the computed phase velocities with a stress $C B$ lie on along the theoretical prediction curve. The computed phase velocities with a displacement $\mathrm{CB}$ follow the shape of the theoretical curve. This indicates that phase velocities with a stress $C B$ have a better curve matching than those with a displacement CB. For inducing a uniform lateral deformation is much more difficult than inducing a uniform shear stress at a pile top by a hammer, the mechanical condition set as a stress $\mathrm{CB}$ at the pile top is more reasonable for lateral impacts on embedded concrete piles.

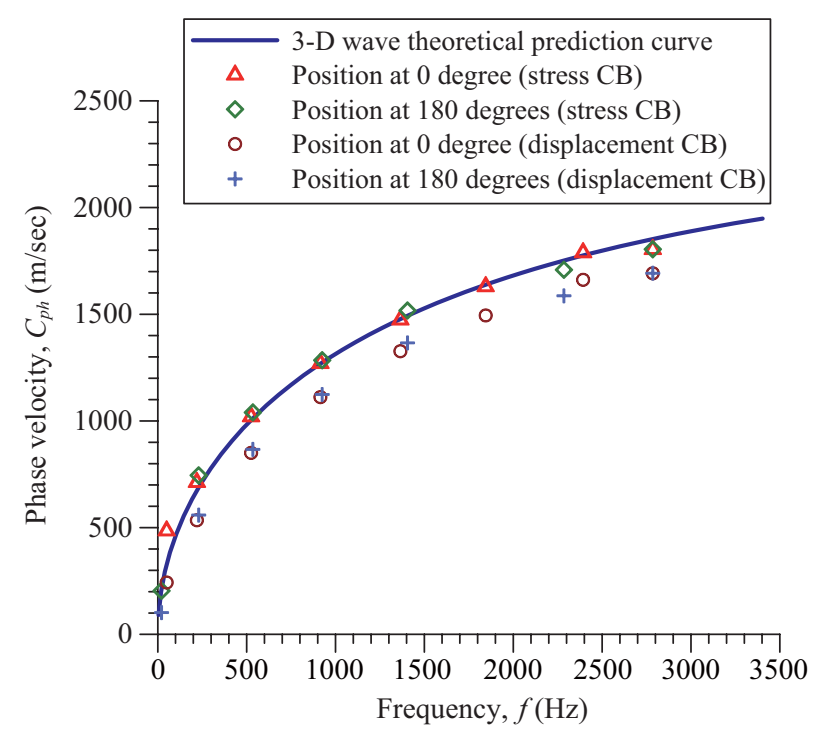

Fig. 8. Phase velocities of flexural waves a prototype concrete pile at measurement positions $0^{\circ}$ and $180^{\circ}$ (radial direction).

\section{Precast Concrete Piles}

A cast-in-place concrete dock is supported by a transfer beam and pile system. Each 254-mm-square precast concrete pile is $15.25 \mathrm{~m}$ in length with design compressive strength of 27.6 MPa. Flexural and longitudinal wave IR tests were conducted on 5 in-service precast concrete piles $[8,9]$. The experimental arrangement of flexural waves induced on these 5 concrete piles is shown as the right side of Fig. 2. Table 5 describes the lengths of piles and material properties, bar wave velocity, shear wave velocity, and Poisson's ratio of concrete.

The orientation of two sensors is consistent with the deformation induced by lateral impacts and the displacement responses along the pile side are like the responses at point $\mathrm{A}$ (assumed $0^{\circ}$ ) in Fig. 5. The maximum displacement theoretically occurs in the radial (impact) direction. Their displacements in the tangential and longitudinal directions can 


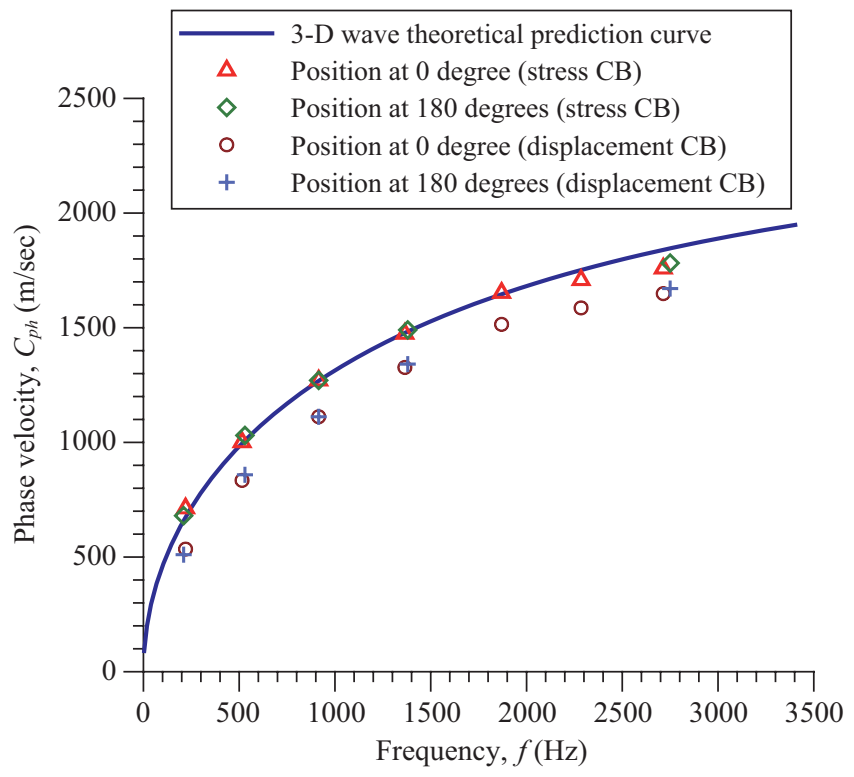

Fig. 9. Phase velocities of flexural waves a prototype concrete pile at measurement positions $0^{\circ}$ and $1^{\circ} 0^{\circ}$ (longitudinal direction).

Table 5. Summary of propagation velocities for 5 precast concrete piles $[8,9]$.

\begin{tabular}{|c|c|c|c|c|}
\hline Pile & Length $(\mathrm{m})$ & $C_{\text {bar }}(\mathrm{m} / \mathrm{sec})$ & $C_{s}(\mathrm{~m} / \mathrm{sec})$ & $v$ \\
\hline 1 & 15.76 & 4026 & 2623 & 0.18 \\
\hline 2 & 16.0 & 4300 & 2806 & 0.18 \\
\hline 3 & 15.99 & 4026 & 2593 & 0.19 \\
\hline 4 & 15.76 & 4026 & 2593 & 0.21 \\
\hline 5 & 16.0 & 4184 & 2562 & 0.20 \\
\hline
\end{tabular}

Note 1: Lengths of piles indicate the total length of the flexural waves propagating through a precast pile, transfer beam, and castin-place concrete dock.

Note 2: $C_{b a r}$ is the bar wave velocity, $C_{s}$ is the shear wave velocity, and $v$ is the Poisson's ratio of concrete.

be negligible due to their superstructure constraints. A typical radial-direction acceleration spectrum obtained from a flexural wave IR test in a dock concrete pile is shown in Fig. 10.

The resonant frequencies corresponding to the first 39 resonant numbers are indicated in Table 6. The resonant number is listed in the first column of Table 6. The similar identified resonant frequencies on upper and lower sensors in the radial direction are listed in the second and third columns of Table 6, respectively. Some resonant frequencies are not identified in the FFT spectrum. The possible causes are an FFT spectrum with a lower resolution due to a lower sampling rate in testing or the FFT responses masked by adjacent peaks. The similar phase velocities with stress and displacement CBs are computed in the rest columns of Table 6.

A typical relation chart for phase velocity and frequency measured by flexural wave IR testing is plotted in Fig. 11. The computed phase velocities at resonant frequencies monotoni-

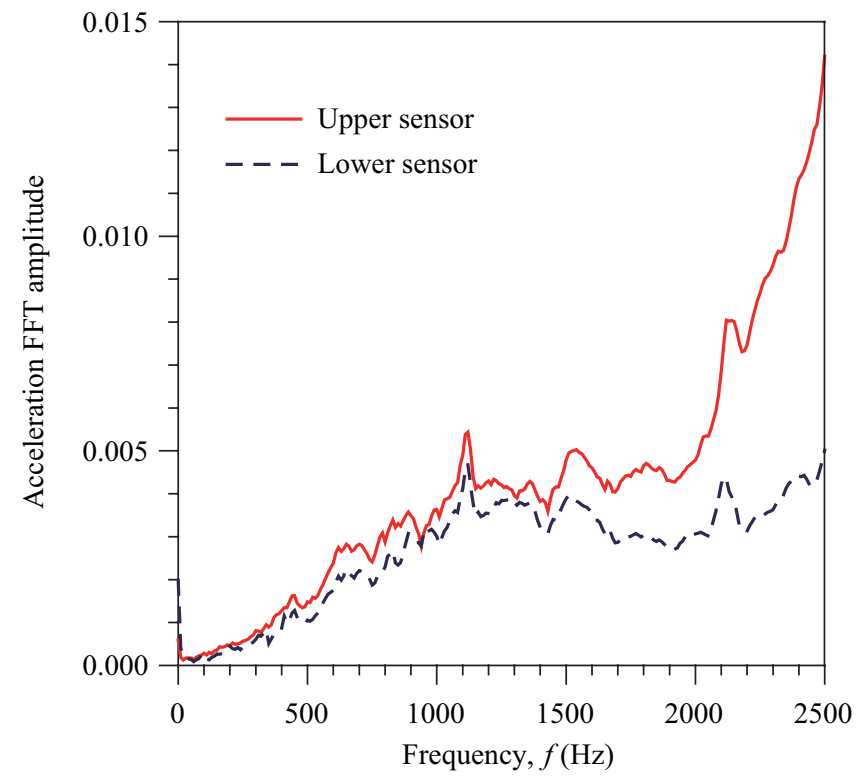

Fig. 10. Transient-state flexural wave response spectrum in a partially exposed concrete pile.

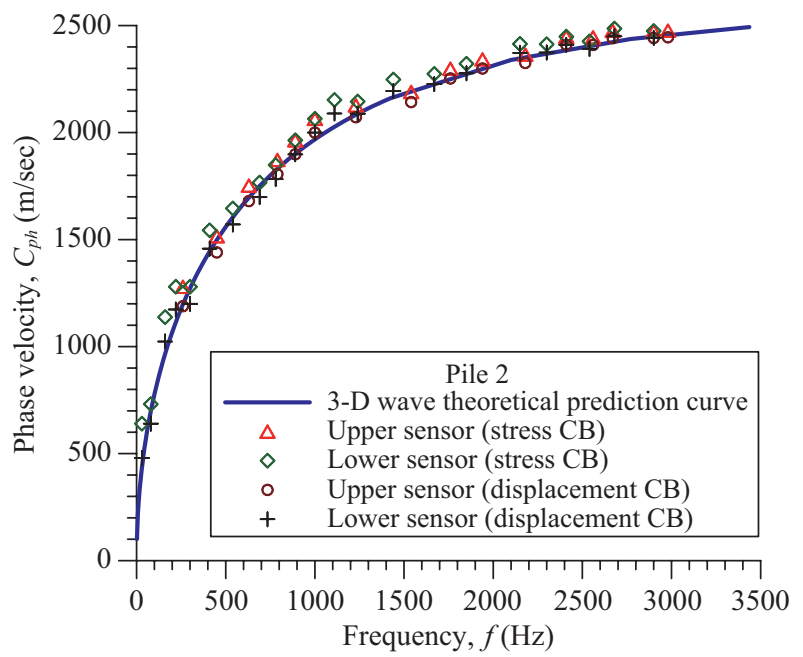

Fig. 11. Phase velocities of flexural waves in a partially exposed concrete pile measured by two sensors.

cally increase with frequency for upper and lower sensors. There is a good match for phase velocities between 3-D wave theoretical prediction curves and flexural wave IR testing results for frequency up to $3,000 \mathrm{~Hz}$. The analysis results agree with the conclusions published in $[4,11,16]$. Both computed phase velocity points for stress and displacement CBs fall around the theoretical prediction curve (see Fig. 12). The result implies that the real boundary condition lies in between stress and displacement controls for dock concrete piles.

\section{Practical Implication}

The analysis results in embedded prototype concrete piles 
Table 6. Phase velocity computation using measured resonant frequency in the radial direction in Pile 2.

\begin{tabular}{|c|c|c|c|c|c|c|}
\hline \multirow[b]{3}{*}{$n$} & \multirow{3}{*}{$\begin{array}{c}\text { Upper sensor } \\
\qquad f_{n}\end{array}$} & \multirow{3}{*}{$\begin{array}{c}\text { Lower sensor } \\
f_{n}\end{array}$} & \multirow{2}{*}{\multicolumn{2}{|c|}{$\begin{array}{c}\text { Stress control boundary } \\
C_{p h}\end{array}$}} & \multirow{2}{*}{\multicolumn{2}{|c|}{$\begin{array}{c}\text { Displacement control boundary } \\
C_{p h}\end{array}$}} \\
\hline & & & & & & \\
\hline & & & Upper sensor & Lower sensor & Upper sensor & Lower sensor \\
\hline 1 & $\mathrm{~N} / \mathrm{I}$ & $\mathrm{N} / \mathrm{I}$ & $\mathrm{N} / \mathrm{I}$ & $\mathrm{N} / \mathrm{I}$ & $\mathrm{N} / \mathrm{I}$ & $\mathrm{N} / \mathrm{I}$ \\
\hline 2 & $\mathrm{~N} / \mathrm{I}$ & 30 & $\mathrm{~N} / \mathrm{I}$ & 640 & $\mathrm{~N} / \mathrm{I}$ & 480 \\
\hline 3 & $\mathrm{~N} / \mathrm{I}$ & $\mathrm{N} / \mathrm{I}$ & $\mathrm{N} / \mathrm{I}$ & $\mathrm{N} / \mathrm{I}$ & $\mathrm{N} / \mathrm{I}$ & $\mathrm{N} / \mathrm{I}$ \\
\hline 4 & $\mathrm{~N} / \mathrm{I}$ & 80 & $\mathrm{~N} / \mathrm{I}$ & 731 & $\mathrm{~N} / \mathrm{I}$ & 640 \\
\hline 5 & $\mathrm{~N} / \mathrm{I}$ & 160 & $\mathrm{~N} / \mathrm{I}$ & 1138 & $\mathrm{~N} / \mathrm{I}$ & 1024 \\
\hline 6 & $\mathrm{~N} / \mathrm{I}$ & 220 & $\mathrm{~N} / \mathrm{I}$ & 1280 & $\mathrm{~N} / \mathrm{I}$ & 1173 \\
\hline 7 & 260 & $\mathrm{~N} / \mathrm{I}$ & 1280 & $\mathrm{~N} / \mathrm{I}$ & 1189 & $\mathrm{~N} / \mathrm{I}$ \\
\hline 8 & $\mathrm{~N} / \mathrm{I}$ & 300 & $\mathrm{~N} / \mathrm{I}$ & 1280 & $\mathrm{~N} / \mathrm{I}$ & 1200 \\
\hline 9 & $\mathrm{~N} / \mathrm{I}$ & 410 & $\mathrm{~N} / \mathrm{I}$ & 1544 & $\mathrm{~N} / \mathrm{I}$ & 1458 \\
\hline 10 & 450 & $\mathrm{~N} / \mathrm{I}$ & 1516 & $\mathrm{~N} / \mathrm{I}$ & 1440 & $\mathrm{~N} / \mathrm{I}$ \\
\hline 11 & $\mathrm{~N} / \mathrm{I}$ & 540 & $\mathrm{~N} / \mathrm{I}$ & 1646 & $\mathrm{~N} / \mathrm{I}$ & 1571 \\
\hline 12 & 630 & $\mathrm{~N} / \mathrm{I}$ & 1753 & $\mathrm{~N} / \mathrm{I}$ & 1680 & $\mathrm{~N} / \mathrm{I}$ \\
\hline 13 & $\mathrm{~N} / \mathrm{I}$ & 690 & $\mathrm{~N} / \mathrm{I}$ & 1766 & $\mathrm{~N} / \mathrm{I}$ & 1698 \\
\hline 14 & 790 & 780 & 1873 & 1849 & 1806 & 1783 \\
\hline 15 & 890 & 890 & 1964 & 1964 & 1899 & 1899 \\
\hline 16 & 1000 & 1000 & 2064 & 2064 & 2000 & 2000 \\
\hline 17 & $\mathrm{~N} / \mathrm{I}$ & 1110 & $\mathrm{~N} / \mathrm{I}$ & 2153 & $\mathrm{~N} / \mathrm{I}$ & 2089 \\
\hline 18 & $\mathrm{~N} / \mathrm{I}$ & $\mathrm{N} / \mathrm{I}$ & $\mathrm{N} / \mathrm{I}$ & $\mathrm{N} / \mathrm{I}$ & $\mathrm{N} / \mathrm{I}$ & $\mathrm{N} / \mathrm{I}$ \\
\hline 19 & 1230 & 1240 & 2128 & 2145 & 2072 & 2088 \\
\hline 20 & $\mathrm{~N} / \mathrm{I}$ & $\mathrm{N} / \mathrm{I}$ & $\mathrm{N} / \mathrm{I}$ & $\mathrm{N} / \mathrm{I}$ & $\mathrm{N} / \mathrm{I}$ & $\mathrm{N} / \mathrm{I}$ \\
\hline 21 & $\mathrm{~N} / \mathrm{I}$ & 1440 & $\mathrm{~N} / \mathrm{I}$ & 2248 & $\mathrm{~N} / \mathrm{I}$ & 2194 \\
\hline 22 & $\mathrm{~N} / \mathrm{I}$ & $\mathrm{N} / \mathrm{I}$ & $\mathrm{N} / \mathrm{I}$ & $\mathrm{N} / \mathrm{I}$ & $\mathrm{N} / \mathrm{I}$ & $\mathrm{N} / \mathrm{I}$ \\
\hline 23 & 1540 & $\mathrm{~N} / \mathrm{I}$ & 2190 & $\mathrm{~N} / \mathrm{I}$ & 2143 & $\mathrm{~N} / \mathrm{I}$ \\
\hline 24 & $\mathrm{~N} / \mathrm{I}$ & 1670 & $\mathrm{~N} / \mathrm{I}$ & 2274 & $\mathrm{~N} / \mathrm{I}$ & 2227 \\
\hline 25 & 1760 & $\mathrm{~N} / \mathrm{I}$ & 2299 & $\mathrm{~N} / \mathrm{I}$ & 2253 & $\mathrm{~N} / \mathrm{I}$ \\
\hline 26 & $\mathrm{~N} / \mathrm{I}$ & 1850 & $\mathrm{~N} / \mathrm{I}$ & 2322 & $\mathrm{~N} / \mathrm{I}$ & 2277 \\
\hline 27 & 1940 & $\mathrm{~N} / \mathrm{I}$ & 2343 & $\mathrm{~N} / \mathrm{I}$ & 2299 & $\mathrm{~N} / \mathrm{I}$ \\
\hline 28 & $\mathrm{~N} / \mathrm{I}$ & $\mathrm{N} / \mathrm{I}$ & $\mathrm{N} / \mathrm{I}$ & $\mathrm{N} / \mathrm{I}$ & $\mathrm{N} / \mathrm{I}$ & $\mathrm{N} / \mathrm{I}$ \\
\hline 29 & $\mathrm{~N} / \mathrm{I}$ & 2150 & $\mathrm{~N} / \mathrm{I}$ & 2414 & $\mathrm{~N} / \mathrm{I}$ & 2372 \\
\hline 30 & 2180 & $\mathrm{~N} / \mathrm{I}$ & 2365 & $\mathrm{~N} / \mathrm{I}$ & 2325 & $\mathrm{~N} / \mathrm{I}$ \\
\hline 31 & $\mathrm{~N} / \mathrm{I}$ & 2300 & $\mathrm{~N} / \mathrm{I}$ & 2413 & $\mathrm{~N} / \mathrm{I}$ & 2374 \\
\hline 32 & 2410 & 2410 & 2448 & 2448 & 2410 & 2410 \\
\hline 33 & $\mathrm{~N} / \mathrm{I}$ & $\mathrm{N} / \mathrm{I}$ & $\mathrm{N} / \mathrm{I}$ & $\mathrm{N} / \mathrm{I}$ & $\mathrm{N} / \mathrm{I}$ & $\mathrm{N} / \mathrm{I}$ \\
\hline 34 & 2560 & 2540 & 2445 & 2426 & 2409 & 2391 \\
\hline 35 & 2670 & 2680 & 2476 & 2486 & 2441 & 2450 \\
\hline 36 & $\mathrm{~N} / \mathrm{I}$ & $\mathrm{N} / \mathrm{I}$ & $\mathrm{N} / \mathrm{I}$ & $\mathrm{N} / \mathrm{I}$ & $\mathrm{N} / \mathrm{I}$ & $\mathrm{N} / \mathrm{I}$ \\
\hline 37 & $\mathrm{~N} / \mathrm{I}$ & $\mathrm{N} / \mathrm{I}$ & $\mathrm{N} / \mathrm{I}$ & $\mathrm{N} / \mathrm{I}$ & $\mathrm{N} / \mathrm{I}$ & $\mathrm{N} / \mathrm{I}$ \\
\hline 38 & 2900 & 2900 & 2475 & 2475 & 2442 & 2442 \\
\hline 39 & 2980 & $\mathrm{~N} / \mathrm{I}$ & 2477 & $\mathrm{~N} / \mathrm{I}$ & 2445 & $\mathrm{~N} / \mathrm{I}$ \\
\hline
\end{tabular}

Note $1: n$ is the resonant number, $f_{n}$ is the resonant frequency, $C_{p h}$ is the phase velocity, and N/I indicates not identified.

Note 2: Units of resonant frequency and phase velocity are $\mathrm{Hz}$ and $\mathrm{m} / \mathrm{sec}$, respectively.

and precast concrete piles provide a 3-D flexural wave based interpretation in explaining irregular frequency difference between two consecutive resonant frequencies at low frequencies [23]. Knowing the designate pile length, $L$, and apparent flexural wave velocity, $C_{s}$, the flexural wave IR or IE tests can be applied to evaluate in-situ pile lengths or defect positions if the computed phase velocities corresponding to measured resonant frequencies cannot completely superimpose on 3-D flexural wave prediction curves.

In addition, the identification degree of resonant frequency is affected by length-to-diameter ratio for the higher lengthto-diameter ratio is and the lower identification degree of 


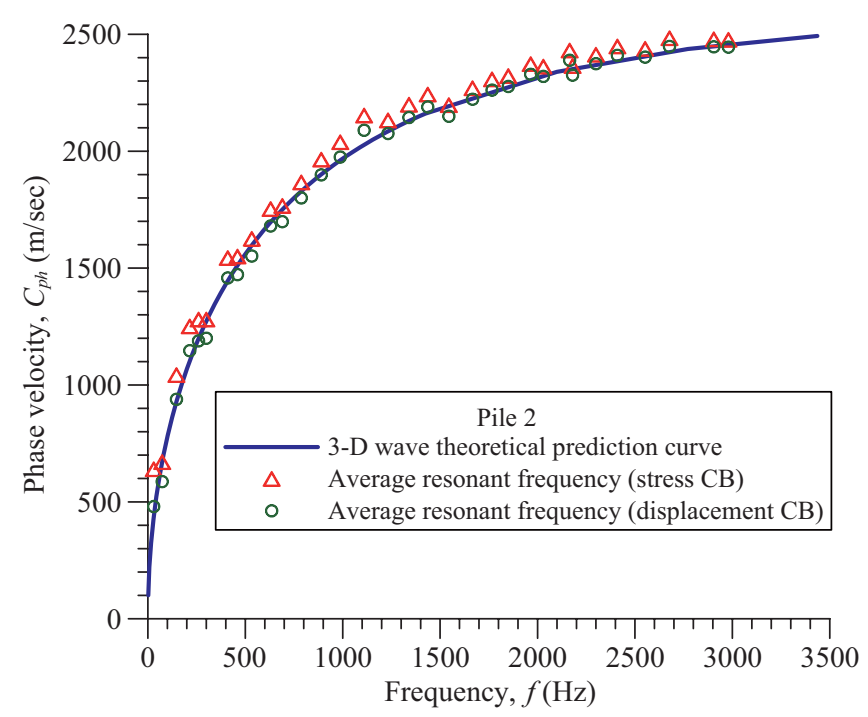

Fig. 12. Average phase velocities of flexural waves in a partially exposed concrete pile.

resonant frequency is. The identification degree of resonant frequency for embedded prototype concrete piles with lengthto-diameter ratios of 6.8 to 8.7 is higher than that for dock precast concrete piles with length-to-diameter ratios of around 17.

\section{CONCULSIONS}

When the top of piles is conveniently accessible to install testing equipment, longitudinal waves are commonly induced to perform IR or IE tests in concrete piles. However, when the pile top is inaccessible as a result of intervening structure, for example transfer beams, or superstructures, only a small portion of the longitudinal wave energy will actually reach the concrete pile. A flexural wave IR or IE test will be a more efficient NDT technique to conduce integrity evaluation in piles. Transient flexural waves are induced by lateral impact on a partially exposed concrete pile side. Based on the analysis results, the following conclusions can be drawn:

1. The resonance technique and first-mode flexural wave curve $\mathrm{F}(1,1)$ are used to find the resonant frequency and phase velocity by knowing the pile dimension and flexural IR testing only. It is a simpler and more efficient method than that by using numerical finite element analysis.

2. The computed phase velocities at measured resonant frequencies have a good agreement with 3-D flexural wave theoretical prediction curves and monotonically increase with frequency at frequencies below around 3,000 $\mathrm{Hz}$.

3. The boundary condition also affects the computed phase wave velocity. For flexural wave IR or IE tests conduced in embedded concrete piles, a stress control boundary can properly represent the mechanical condition for its phase velocities have a better matching with 3-D flexural wave theoretical prediction curves than those with a displacement $\mathrm{CB}$. The real boundary condition lies in between stress and displacement controls for partially exposed concrete piles supporting a dock.

4. In practical, if the designate length and apparent flexural wave velocity are known in a pile, using flexural wave IR or IE tests can evaluate its in-situ dimension characteristics. When the computed phase velocities of resonant frequencies cannot completely superimpose on 3-D flexural wave theoretical curves, the occurrence of breakage and/or major defects could be expected in a pile.

5. For the identification degree of resonant frequency in a flexural wave spectrum, piles with a lower length-to-diameter ratio have a higher value than that for those with a higher length-to-diameter ratio.

\section{APPENDIX}

Stress waves propagate along a finite pile with a length of $L$ fully or partially embedded in uniform soils/rocks. Assuming the position, $z$, equal to zero at a pile top, the pile is represented in an orthogonal cylindrical coordinate $r-\theta-z$ system. The displacement of 1-D longitudinal and flexural wave propagation in a pile at any position $z$ can be expressed as

$$
\begin{aligned}
& u_{z}(z, t)=A_{1} \exp [i(\omega t-k z)]+A_{2} \exp [i(\omega t+k z)] \\
& u_{r}(z, t)=A_{3} \exp [i(\omega t-k z)]+A_{4} \exp [i(\omega t+k z)]
\end{aligned}
$$

respectively, where $\omega$ is the angular frequency equal to $2 \pi f, t$ is the time, $k$ is the wave number equal to $2 \pi / \lambda, A_{1}$ and $A_{2}$ are the displacement amplitude of longitudinal waves, $A_{3}$ and $A_{4}$ are the displacement amplitude of flexural waves, $f$ is the frequency, and $\lambda$ is the wavelength.

In general, the pile top is allowed to take a relatively higher deformation as a pile is subjected to impacts at its top. The mechanical condition on a pile bottom is often regarded as having a very low deformation. Such boundary conditions are usually simulated as one-free-end and one-fixed-end boundary conditions in a pile. Usually, the displacement is assumed as zero at the fixed-end boundary condition. The wave modes in a finite length pile are reflected without phase change as a wave of the same type but traveling in the opposite direction [4]. However, there are two possibilities for the free-end boundary condition, a given displacement or given stress boundary condition. In this research, such two boundary conditions are simplified as displacement control boundary (CB) and stress $\mathrm{CB}$, respectively.

For longitudinal waves, the displacement $\mathrm{CB}$ at a pile top is

$$
u_{z}(0, t)=A_{1} \exp (i \omega t)+A_{2} \exp (i \omega t)=A_{0 z} \exp (i \omega t)
$$

where $A_{0 z}$ is the displacement amplitude of incident longitu- 
dinal waves. The displacement $\mathrm{CB}$ at a pile bottom is

$$
u_{z}(L, t)=A_{1} \exp [i(\omega t-k L)]+A_{2} \exp [i(\omega t+k L)]=0
$$

The displacement solution of longitudinal waves is

$$
u_{z}(z, t)=\frac{A_{0 z} \sin [k(L-z)]}{\sin (k L)} \exp (i \omega t)
$$

This indicates that the amplitude of the displacement is infinite when its denominator is equal to zero [2]. The evaluation of resonance solutions for longitudinal waves is summarized as

$$
k L=n \pi
$$

where $n$ is the positive integral resonant number.

For longitudinal waves, the stress $\mathrm{CB}$ at a pile top is

$$
\sigma_{z z}(0, t)=T_{0 z} \exp (i \omega t)=E \frac{\partial u_{z}}{\partial z}
$$

where $T_{0 z}$ is the stress amplitude of incident longitudinal waves. The stress $\mathrm{CB}$ at a pile bottom is

$$
u_{z}(L, t)=A_{1} \exp [i(\omega t-k L)]+A_{2} \exp [i(\omega t+k L)]=0
$$

The displacement solution of longitudinal waves is

$$
u_{z}(z, t)=-\frac{T_{0 z} \sin [k(L-z)]}{k E \cos (k L)} \exp (i \omega t)
$$

This indicates that the amplitude of the displacement is infinite when its denominator is equal to zero [2]. The evaluation of resonance solutions for longitudinal waves is

$$
k L=(2 n-1) \pi
$$

For flexural waves, the displacement $\mathrm{CB}$ at a pile top is

$u_{r}(0, t)=A_{3} \exp (i \omega t)+A_{4} \exp (i \omega t)=A_{0 r} \exp (i \omega t)$

where $A_{0 r}$ is the displacement amplitude of incident flexural waves. The displacement $\mathrm{CB}$ at a pile bottom is

$$
u_{r}(L, t)=A_{3} \exp [i(\omega t-k L)]+A_{4} \exp [i(\omega t+k L)]=0
$$

The displacement solution of flexural waves is

$$
u_{r}(z, t)=\frac{A_{0 r} \sin [k(L-z)]}{\sin (k L)} \exp (i \omega t)
$$

This indicates that the amplitude of the displacement is infinite when its denominator is equal to zero [2]. The evaluation of resonance solutions for flexural waves is expressed as

$$
k L=n \pi
$$

For flexural waves, the stress $\mathrm{CB}$ at a pile top is

$$
\sigma_{z r}(0, t)=T_{0 r} \exp (i \omega t)=G \frac{\partial u_{r}}{\partial z}
$$

where $T_{0 r}$ is the stress amplitude of incident flexural waves. The stress $\mathrm{CB}$ at a pile bottom is

$u_{r}(L, t)=A_{3} \exp [i(\omega t-k L)]+A_{4} \exp [i(\omega t+k L)]=0$

The displacement solution of flexural waves is

$$
u_{r}(z, t)=-\frac{T_{0 r} \sin [k(L-z)]}{k G \cos (k L)} \exp (i \omega t)
$$

This indicates that the amplitude of the displacement is infinite when its denominator is equal to zero [2]. The evaluation of resonance solutions for flexural waves is

$$
k L=(2 n-1) \pi
$$

Combining the resonance solutions of longitudinal or flexural waves traveling in a finite pile, the resonance solutions are dependent upon their boundary conditions described as Combining the resonance solutions of longitudinal or flexural waves traveling in a finite pile, the resonance solutions are dependent upon their boundary conditions described as

$$
\begin{gathered}
k L=n \pi \text { for displacement CB } \\
k L=(2 n-1) \pi \text { for stress CB }
\end{gathered}
$$

The resonant wavelength of waves, $\lambda_{d}$, with a displacement $\mathrm{CB}$ and resonant wavelength of waves, $\lambda_{s}$, with a stress CB are

$$
\begin{gathered}
\lambda_{d}=\frac{2 L}{n} \\
\lambda_{s}=\frac{4 L}{2 n-1}
\end{gathered}
$$

respectively.

\section{REFERENCES}

1. Baker, C. N., Parikh, G., Briaud, J. L., Drumright, E. E., and Mensah, F., Drilled Shafts for Bridge Foundations, FHWA Report No. FHWA-RD- 
92-004, Federal Highway Administration, McLean, VA, U.S.A. (1993).

2. Bedford, A. and Drumheller, A. S., Introduction to Elastic Wave Propagation, John Wiley \& Sons Ltd., New York, NY, U.S.A., pp. 83-89 (1994).

3. Carino, N. J., "Stress wave propagation methods," in: Malhotra, V. M. and Carino, N. J. (Eds.), CRC Handbook on Nondestructive of Concrete, CRC Press, Boca Raton, FL, U.S.A., pp. 14-1 14-23 (2004).

4. Chao, H.-C., An Experimental Model for Non-Destructive Evaluation on Pile Foundations Using Guided Wave Approach, Ph.D. Dissertation, Department of Civil and Environmental Engineering, Northwestern University, Evanston, IL, U.S.A. (2002).

5. Chen, S. and Kim, R., "Dispersive wave propagation analysis for condition assessment of marine timber piles," in: Townsend, F. C., Hussein, M., and McVay, M. C. (Eds), Proceedings of the $5^{\text {th }}$ International Conference on Application of Stress-Wave Theory to Piles, Orlando, FL, U.S.A., pp. 721-732 (1996)

6. Davis, A. G. and Dunn, C. S., "From theory to field experience with nondestructive vibration testing of piles," Proceedings of the Institution of Civil Engineers, Part 2: Research and Theory, Vol. 57, pp. 571-593 (1974)

7. Douglas, R. A. and Holt, J. D., Determining Length of Installed Timber Pilings by Dispersive Wave Propagating Methods, FHWA Report No. FHWA-NC-94-001, Federal Highway Administration, McLean, VA, U.S.A (1994).

8. Finno, R. J., Chao, H.-C., and Lynch, J. J., Nondestructive Evaluation of In Situ Concrete Piles at the Advanced Waterfront Technology Test Sites, Port Hueneme, California, report for the Naval Facilities Engineering Service Center, Washington, D. C., U.S.A. (2001).

9. Finno, R. J. and Lynch, J., Non-Destructive Evaluation of In Situ Concrete Piles at Wharf 5, Port Hueneme, California, report for the Naval Facilities Engineering Service Center, Washington, D. C., U.S.A. (2002)

10. Finno, R. J., Popovics, J. S., Hanifah, A. A., Kath, W. L., Chao, H.-C., and $\mathrm{Hu}$, Y.-H., "Guided wave interpretation of surface reflection techniques for deep foundations," Italian Geotechnical Journal, Vol. 35, No. 1, pp. 76-91 (2001).

11. Finno, R. J., Wang, H., and Lynch, J., "Flexural waves in nondestructive evaluation of drilled shafts," Proceedings of Conference on Quality Assurance/Quality Control $(Q A / Q C)$ and Verification for Drilled Shafts, Anchors, and Micropiles, ADSC, Dallas, TX, U.S.A. (2005).

12. Gassman, S.L., Impulse Response Evaluation of Inaccessible Foundations, Ph.D. Dissertation, Department of Civil Engineering, Northwestern
University, Evanston, IL, U.S.A. (1997).

13. Hanifah, A. A., A Theoretical Evaluation of Guided Waves in Deep Foundations, Ph.D. Dissertation, Department of Civil Engineering, Northwestern University, Evanston, IL, U.S.A. (1999).

14. Lin, Y., Sansalone, M. J., and Carino, N. J., "Impact-echo response of concrete shafts," Geotechnical Testing Journal, Vol. 14, No. 2, pp. 121137 (1991)

15. Lundberg, B. and Henchoz, A., "Analysis of elastic waves from two-point strain measurement," Journal of Experimental Mechanics, Vol. 17, No. 6, pp. 213-218 (1977).

16. Lynch, J., Experimental Verification of Flexural Guided Waves in Concrete Cylindrical Piles, Ph.D. Dissertation, Department of Civil and Environmental Engineering, Northwestern University, Evanston, IL, U.S.A. (2007).

17. Olson, L. D., Jalinoos, F., and Aouad, M. F., Determination of Unknown Subsurface Bridge Foundations, NCHRP Project E21-5, Transportation Research Board, National Research Council, Washington, D. C., U.S.A (1995).

18. Qian, Y., Non-Destructive Evaluation of Structural Condition of Timber Piles Using Stress Wave Techniques, Master Thesis, Department of Civil Engineering, North Carolina State University, Raleigh, NC, U.S.A. (1997).

19. Rhodes, P. B., Nondestructive Assessment of Pile Tip Evaluations, Master Thesis, Georgia Institute Technology, Atlanta, GA, U.S.A. (1996).

20. Rix, G. J., Jacobs, L. J., Rhodes, P. B., and Raparelli, R. Q., Nondestructive Assessment of Pile Tip Elevations Using Flexural Waves, Georgia Department of Transportation Project No. 9406, Atlanta, GA, U.S.A. (1995).

21. Wang, H., Theoretical Evaluations of Embedded Plate-Like and Solid Cylindrical Concrete Structures with Guided Waves, Ph.D. Dissertation, Department of Civil and Environmental Engineering, Northwestern University, Evanston, IL, U.S.A. (2004).

22. Wang, H. and Chang, T.-P., "Non-destructive evaluations of in-service concrete piles by flexural wave approach," in: Santos, J. A. (Ed.), Proceedings of the $8^{\text {th }}$ International Conference on the Application of StressWave Theory to Piles: Science, Technology, and Practice, Lisbon, Portugal, pp. 477-484 (2008).

23. Yu, C.-P. and Roesset, J. M., Determination of Pile Lengths Using Flexural Waves, NCHRP Project E21-5, report for Olson Engineering, Inc., Golden, CO, U.S.A. (1995). 